\title{
MAKE ROOM FOR WILDLIFE: A RESOURCE FOR LOCAL PLANNERS AND COMMUNITIES IN THE TUG HILL REGION
}

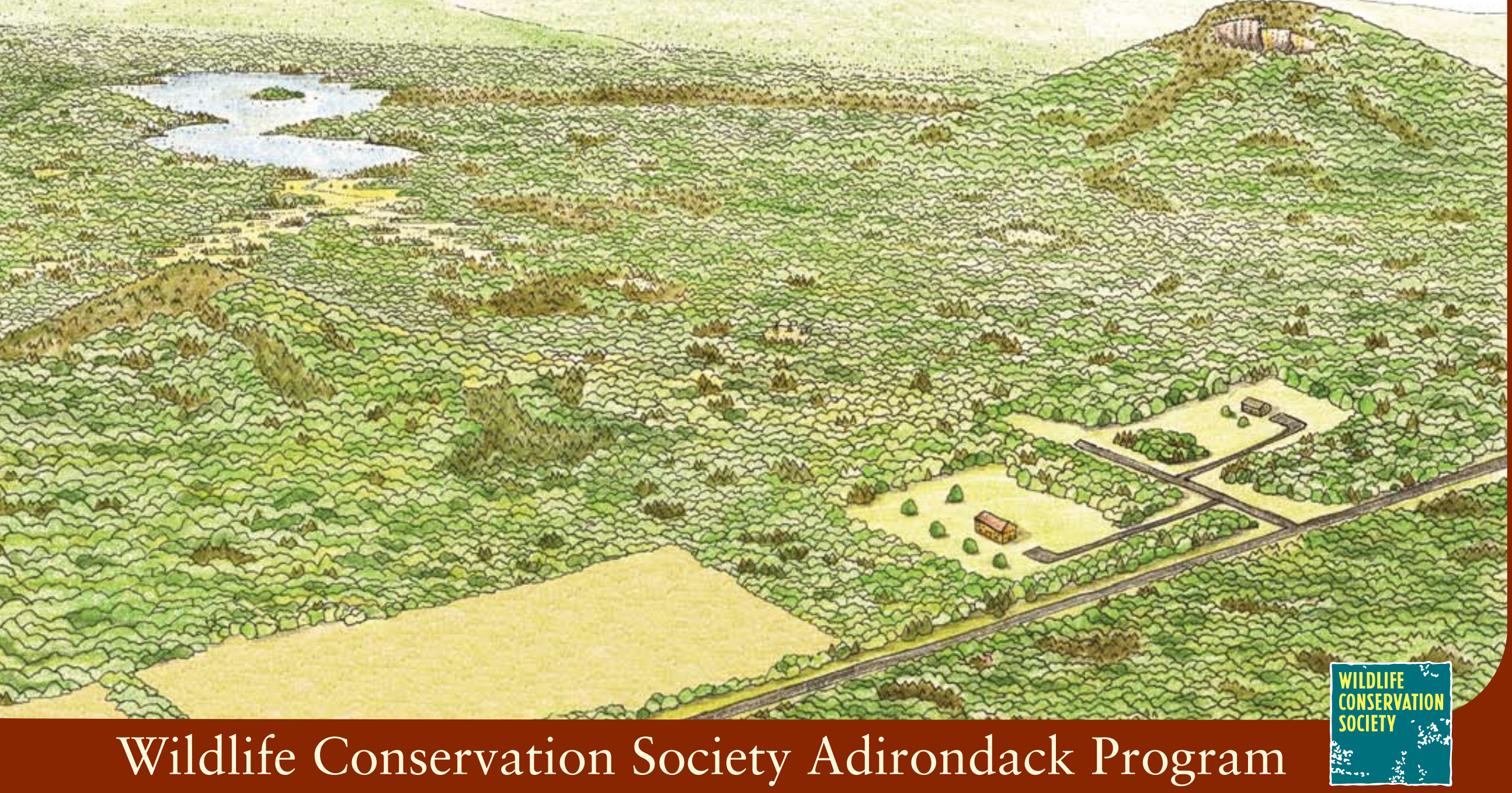




\section{WHAT NATURAL FEATURES ARE IN YOUR TOWN?}

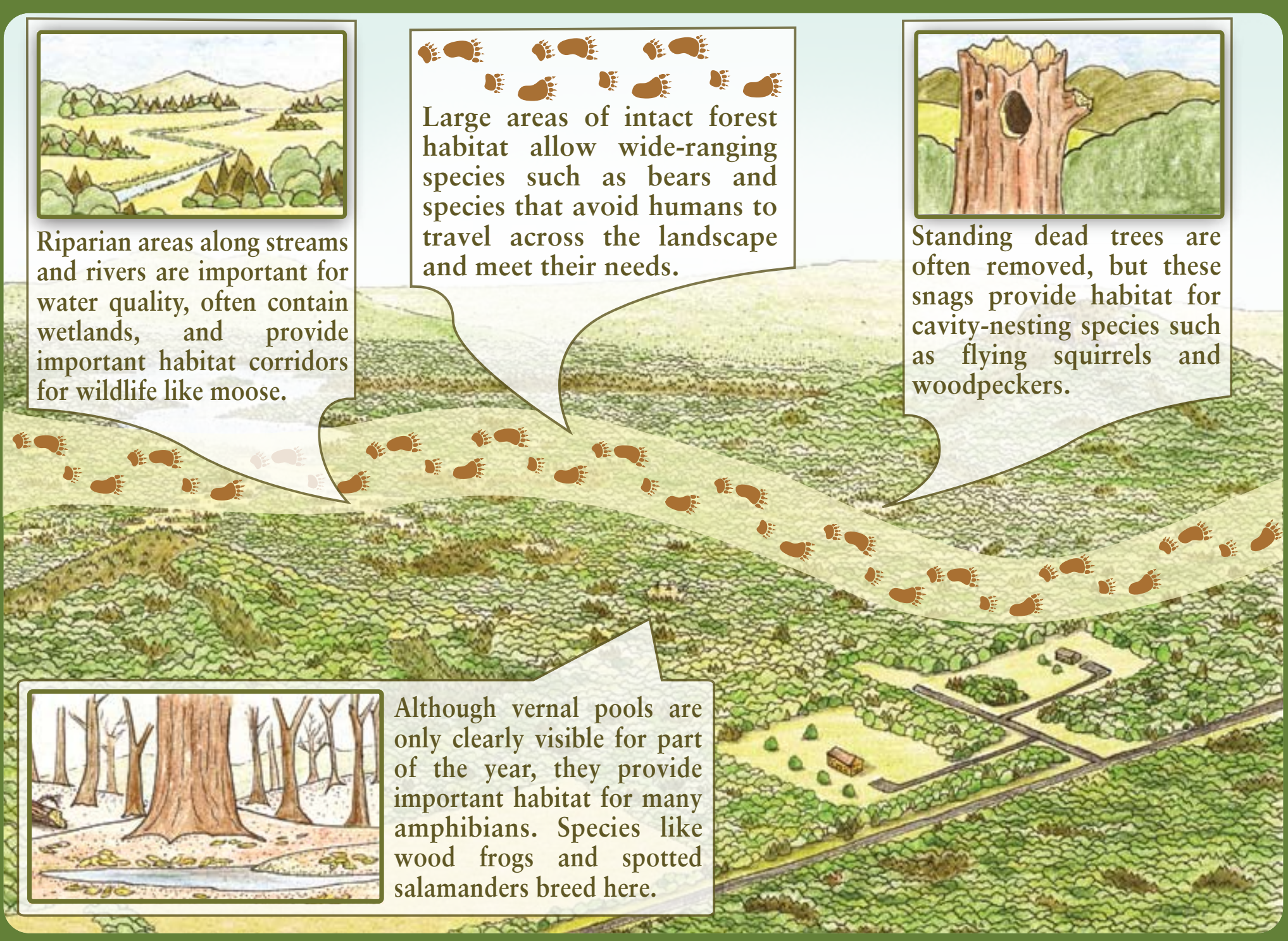

Riparian corridors, vernal pools, large blocks of intact forest, and snags are just a few of the natural features that provide important wildlife habitat in the Adirondack landscape. Features such as these are often overlooked, however. Recognizing and identifying these features is the first step to protecting wildlife, even while pursuing development opportunities. 


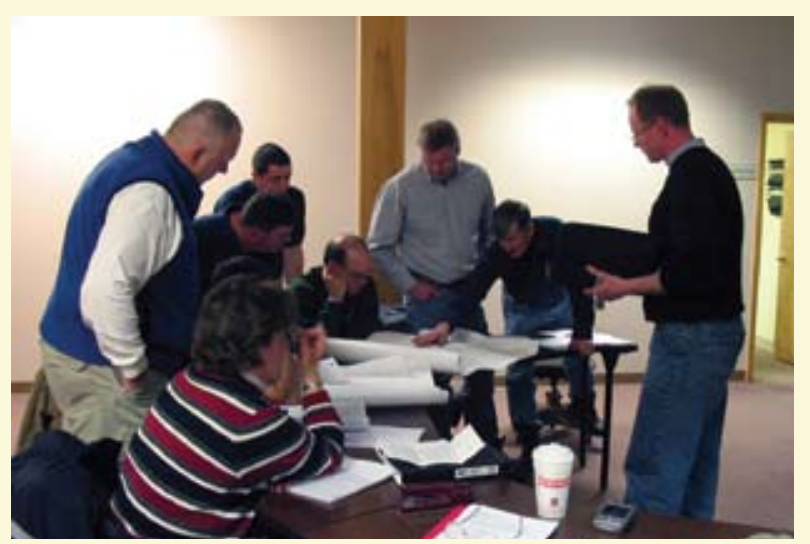

WILDLIFE AND RESIDENTIAL DEVELOPMENT

This pamphlet will help local planners and communities in the Tug Hill region consider wildlife in developing land-use plans and reviewing proposals. To maintain the incredible wildlife found here, Tug Hill residents must be thoughtful-and smart-about how to develop private lands. Intact habitats on these private lands are important to wildlife, especially since private lands constitute over $80 \%$ of the land on Tug Hill.

Town boards, planning boards, and local zoning boards of appeal play an important role in protecting wildlife when reviewing proposals under their jurisdiction and exercising planning as authorized by state law. Habitat loss and fragmentation are two of the most significant threats facing wildlife species in the Tug Hill region and elsewhere. Communities can take advantage of many planning principles and tools in order to plan for growth while minimizing adverse effects, protecting wildlife, and enhancing community values. The guidelines in this brochure offer opportunities to work towards this goal.

\section{IF YOU ARE THINKING ABOUT THE FUTURE OF YOUR COMMUNITY}

Whether you are working on a new comprehensive plan, land-use code, subdivision regulations, or other local planning tools, you have an opportunity to shape your community in the long term. Under state law, towns and villages in New York have reasonably broad authority to adopt local planning and land use laws. Use this power for the long-term benefit of both people and wildlife in your community!

Plan ahead, ask for help, and set goals for conservation-Make wildlife and

biodiversity conservation a primary goal of your planning effort from the outset. Obtain help from local scientists and natural resource managers: New York Natural Heritage Program, New York Department of State, Tug Hill Commission, Tug Hill Tomorrow Land Trust, Wildlife Conservation Society, Soil and Water Conservation Districts, and others.

Identify what you have and what is vulnerable, sensitive, or ecologically important-Good information leads to a strong plan. Gather information about the natural features of your community as part of the planning process. Consult the groups listed above for assistance. Give developers, landowners, and planners within your community access to information to ensure its use in planning future development.

Think regionally-Does your town have forests, rivers, streams, or wetlands that cross municipal boundaries? If you are developing a comprehensive plan, consider making it an intermunicipal plan. If this is not possible, show that your community exists in a wider ecological context.
- Include goals that capture your community's conservation values-If you are developing a comprehensive plan, your work will set the precedent for land-use planning in your community for years to come. Explicitly state the attributes of your natural environment that you wish to protect and preserve.

- Encourage efficient use of

land-Clustering or concentrating development, rather than spreading it out over the landscape, protects open space, protects wildlife habitat, and minimizes need for infrastructure. Adopt local guidelines to encourage clustering or adopt conservation design principles such as conservation overlays to convey the importance of using land efficiently to everyone in the community. Direct growth to existing villages and hamlets.

- Be aware of the variety of tools available for protecting open space-There are many sources of information on regulatory tools such as conservation overlay zones, purchase or transfer of development rights, conservation subdivisions, easements, and cluster or open space zoning for protecting wildlife and habitat in the context of residential development. See the "Getting Started" section of this brochure. 


\section{IF YOU ARE REVIEWILG A SUBDIVISION PROPOSAL}

Subdivisions create an irreversible effect of dividing the landscape and causing habitat loss. However, there are many ways that you can work with developers to minimize the negative impacts of subdivisions.

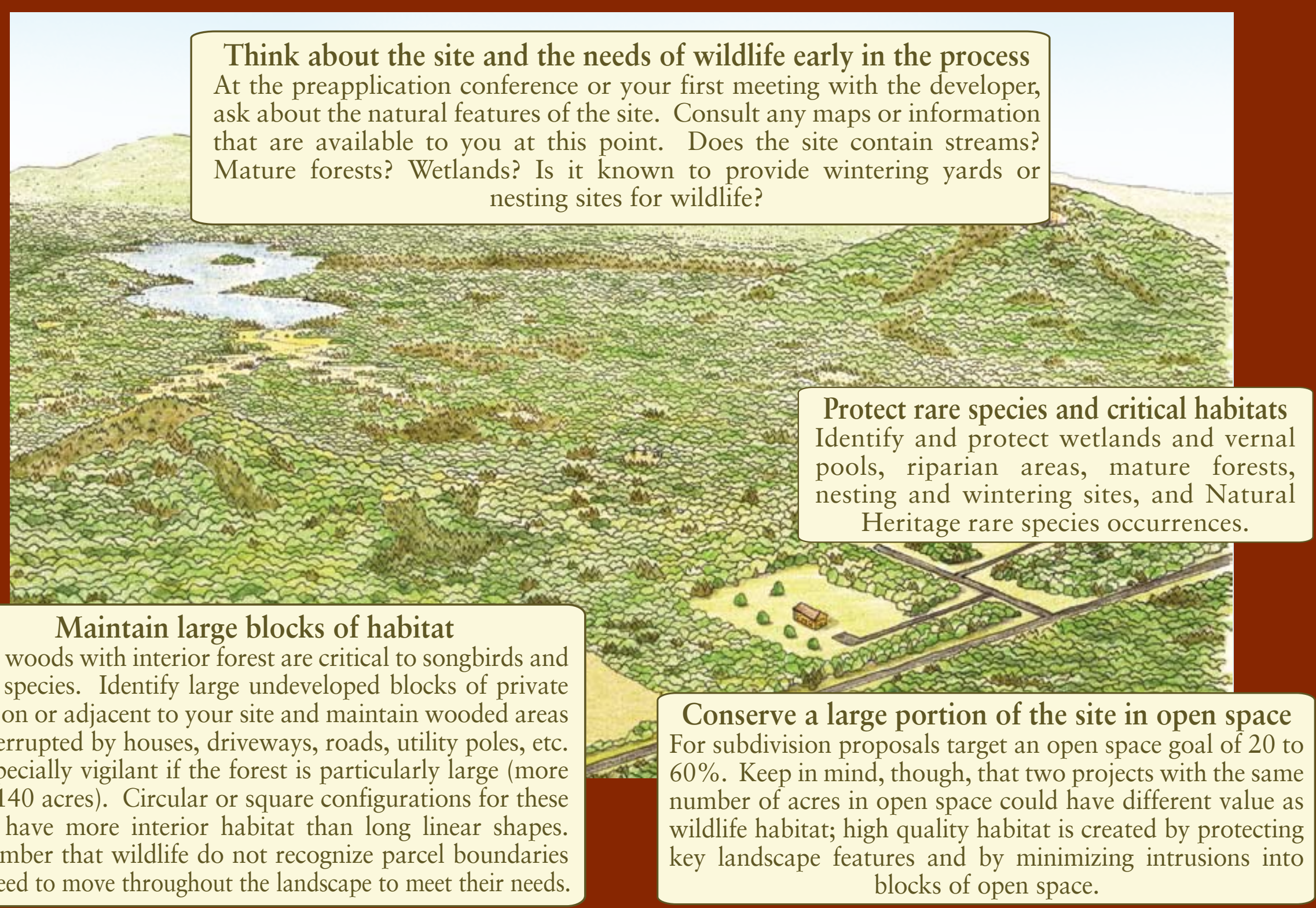

Large woods with interior forest are critical to songbirds and other species. Identify large undeveloped blocks of private lands on or adjacent to your site and maintain wooded areas uninterrupted by houses, driveways, roads, utility poles, etc. Be especially vigilant if the forest is particularly large (more than 140 acres). Circular or square configurations for these areas have more interior habitat than long linear shapes. Remember that wildlife do not recognize parcel boundaries and need to move throughout the landscape to meet their needs. blocks of open space. 
INSTEAD OF THIS

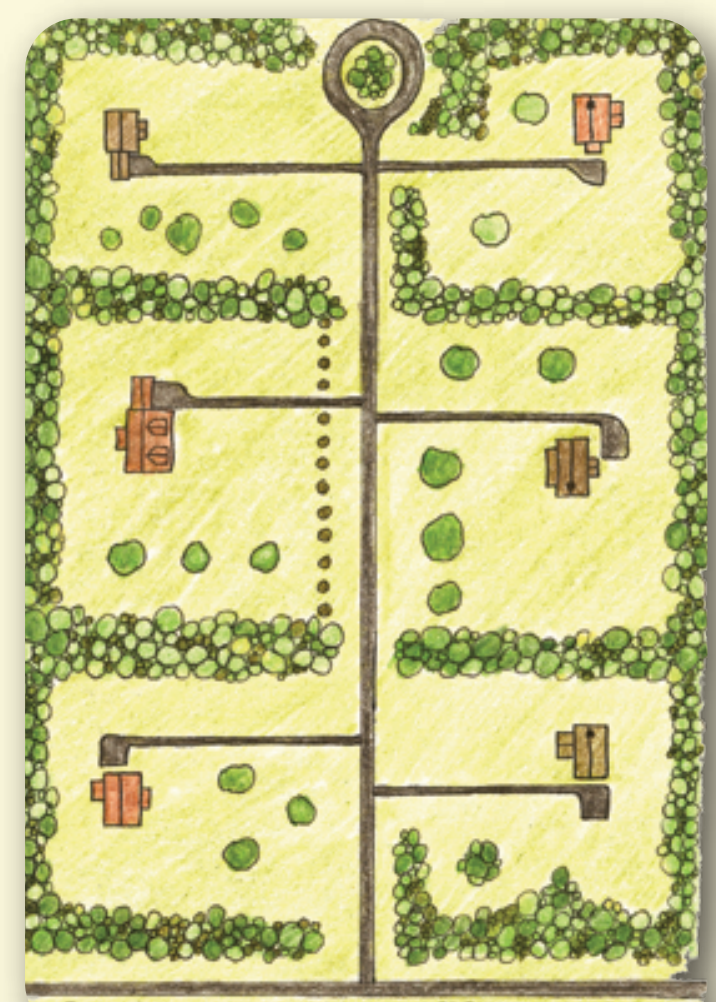

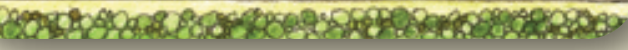

\section{STRIVE FOR THIS}

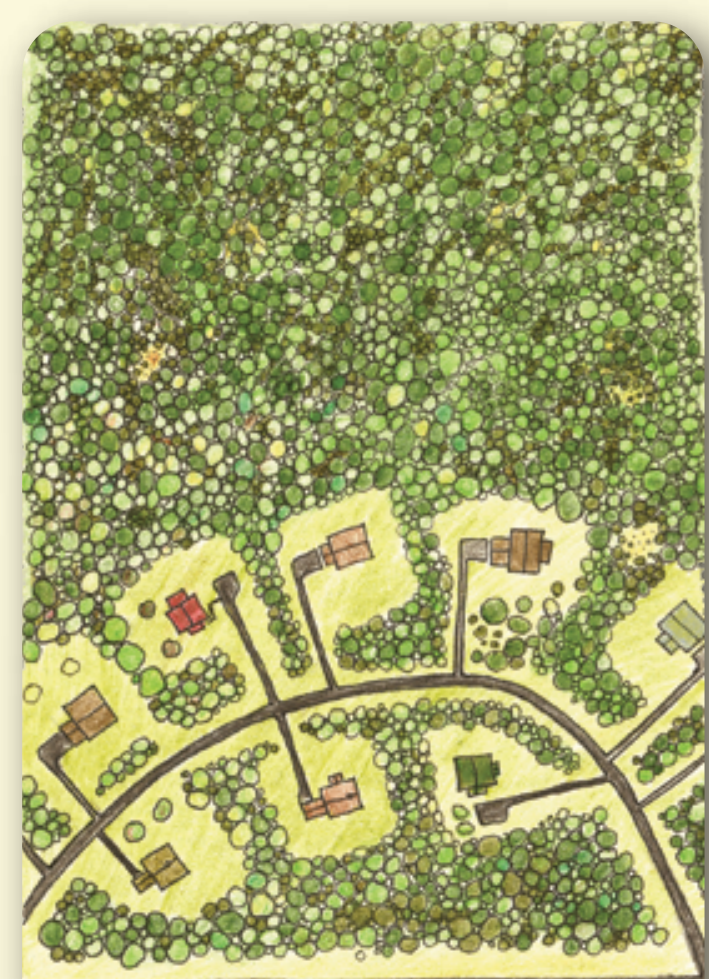

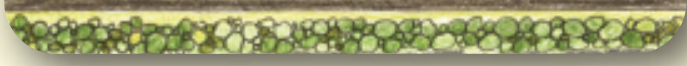

Clustering homes helps maintain most of the site in a natural condition, preserves large contiguous habitat blocks, reduces new road construction, and limits the area of human disturbance. Cluster homes whenever possible, and minimize the footprint of homes by limiting the allowable size of lawns. Clustering and minimizing new road construction will reduce the carbon emissions of a projet. Clustering also lowers road maintenance costs by limiting new road construction. 


\section{INSTEAD OF THIS}

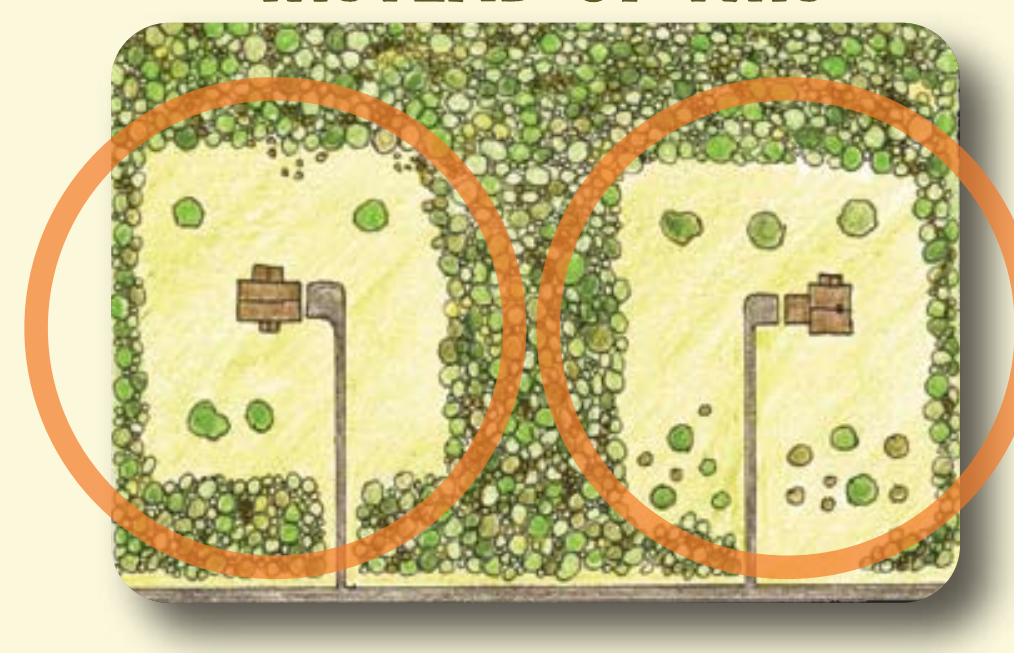

\section{STRIVE FOR THIS}

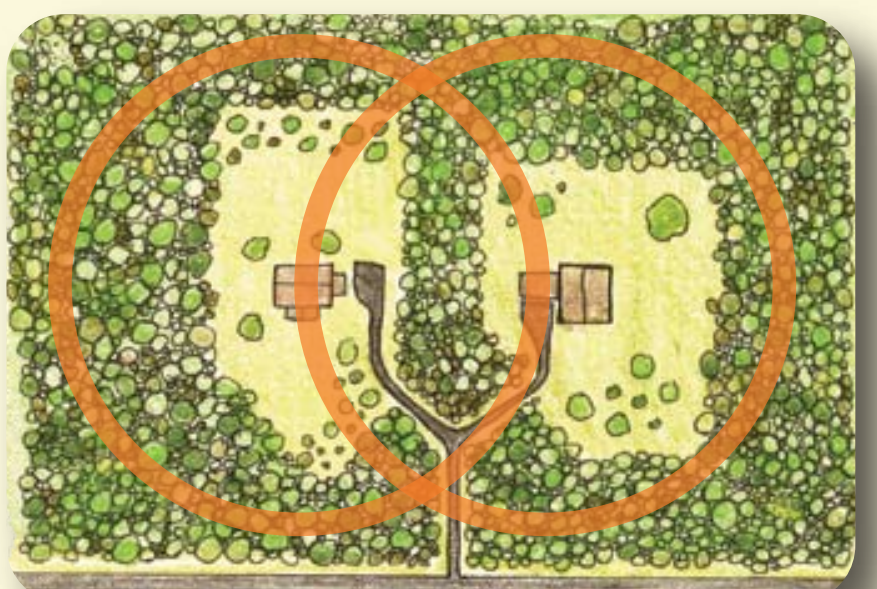

Humans and their activities have impacts on surrounding wildlife. These impacts extend out at least 500 - 600 feet from homes. By locating homes closer together, these zones of influence overlap, lessening the overall area of impact.

\section{Emphasize proper subdivision design}

Avoid sensitive features by adjusting the configuration of lots or prescribing the buildable areas within lots. Work with the applicant to determine an appropriate design for the site. Consider the number, size, location, and density of new parcels, as well as the location of new infrastructure, such as roads, and strive to minimize these impacts. 


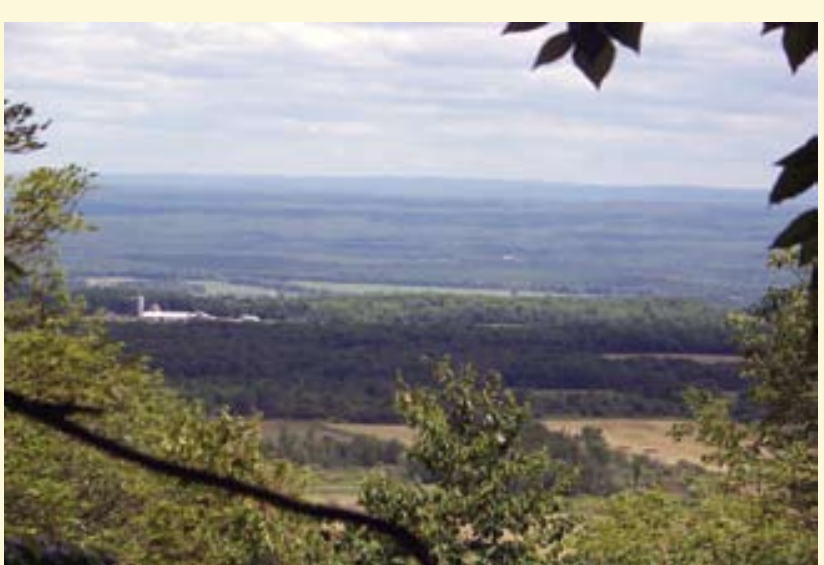

\section{SEEKING SENSE IN SEQR}

Whether you are considering adopting a comprehensive plan, reviewing a site plan or subdivision proposal, or considering a variance, you are probably obligated to comply with SEQR, the State Environmental Quality Review Act. Impacts to open space, water quality, and plants and animals are all considerations that agencies must evaluate in determining the significance of an action under SEQR. Type I and Unlisted actions require an Environmental Assessment Form (either short or full) to be completed. The lead agency (often a local town or planning board) must make a discretionary judgment about the magnitude and importance of these impacts. The Environmental Assessment Form provides a framework for specific factors to consider, including impacts to habitat and wildlife. Although many actions with some potential impact on wildlife may ultimately not require a detailed SEQR review, local agencies should take advantage of the opportunity to consider all of the potential impacts of an action on the community.
IF YOU ARE REVIEWIING A STIE PLAN

Understand the site and its context Gather available information and ask the applicant questions early in the process about the natural features and wildlife habitats of the site, and keep the big picture, such as nearby features, in mind.

\section{Understand the proposal and identify potential impacts}

Will the proposed activity impact rare species or critical habitats? Will it infringe upon large forest blocks, or create new roads and edges? Edges between forests and open space created by lawns, roads, and other features can negatively influence some kinds of wildlife. Identify these ecological impacts, and identify ways you can work with the applicant to minimize or mitigate them.

\section{Maintain appropriate buffers}

Development should be separated from features like rivers, lakes, streams and wetlands to protect water quality and maintain wildlife's ability to use and move along these features. Avoid locating development within 300 feet of these features.

\section{Minimize the spread of non-native, invasive species}

Encourage or mandate using native species in landscaping plans, and minimize roads and edges, which provide pathways for invasive species.

\section{Consider the type and timing of construction activities}

Avoid undertaking construction activities during critical amphibian movement and migration times or bird nesting seasons (primarily spring and early summer). Time construction in late summer, fall, (and winter, where possible) to minimize impacts to many wildlife species that breed in spring in the Adirondacks.

\section{GETTING STARTED}

Integrating wildlife needs into local planning efforts may seem like a daunting task but many resources exist to assist you in this rewarding effort. If you have questions about this document, would like links to or lists of additional resources, or would like to work with us to determine ways that you can protect wildlife habitat through local planning in your community, please visit our website www.wcs.org/adirondacks or contact us at accp@wcs.org

\section{ABOUT US}

This brochure is a partnership between the Wildlife Conservation Society Adirondack Program, and the Tug Hill Tomorrow Land Trust (THTLT). It is based on an earlier edition for the Adirondacks.

The Wildlife Conservation Society saves wildlife and wild lands through careful science, global conservation and education. The WCS Adirondack Program promotes healthy communities and wildlife conservation in the Adirondacks through an information-based, cooperative approach to research, community involvement, and outreach.

THTLT is a nonprofit regional organization that works with private landowners and local governments to protect working forests, farms, recreation and wild lands within the Tug Hill Region. We also work to increase the awareness and appreciation of the region and foster responsible stewardship practices.

We gratefully acknowledge the support of the Doris Duke Charitable Foundation through the Wildlife Action Opportunities Fund for the production of the previous edition of this brochure, and we acknowledge Iroquois Gas Transmission System's Community Grant Program for financial support for this edition.

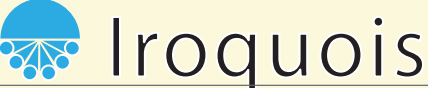




\section{WHICH WILDLIFE WILL THANK YOU?}
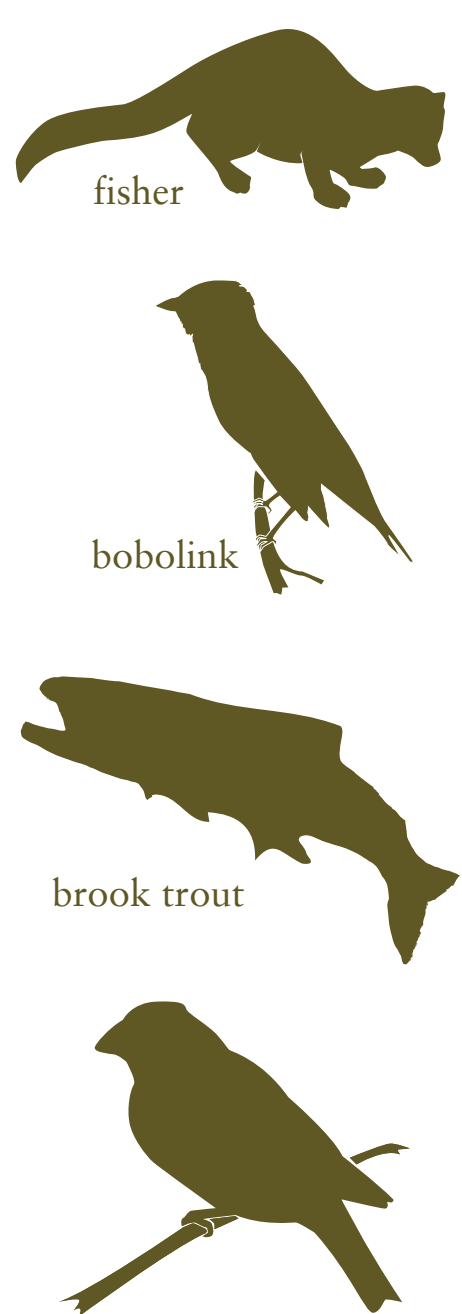

evening grosbeak

\section{Wide-ranging animals}

Black bear, bobcat, fisher, and moose are examples of species that need lots of space and will appreciate planning that protects large, well-connected forest blocks. Wildlife species do not heed political or land-ownership boundaries. Thinking on broader scales and considering daily and yearly movement needs helps maintain healthy wildlife populations.

\section{Amphibians and reptiles}

Amphibians and reptiles are particularly susceptible to the impacts of roads and other fragmenting features because they use a variety of habitat types during their life cycle. Some, like turtles, do not even begin to reproduce until they are quite old $(>20$ years). Minimizing roads and using techniques to make roads as wildlife-friendly and permeable as possible will greatly enhance survivorship of reptiles and amphibians.

\section{Interior forest dwellers}

Edges between forests and openings like roads or lawns pose many dangers, and some species will not use forests that are fragmented by roads and houses.

Maintaining large forest blocks with plenty of interior habitat will ensure suitable areas for species like scarlet tanager and ovenbird.

\section{Small mammals}

Small mammals are a critically important food source for a variety of species like marten, fisher, fox, and coyote. Maintaining snags and downed woody debris associated with old-forest conditions will help maintain habitat to support diverse, abundant small mammal populations. Similarly, minimizing roads and the size of lawns will help curb indiscriminate loss of these species.

\section{Field and farmland dwellers}

Species such as bobolink, eastern meadowlark, and meadow jumping mouse rely on the farmland resources of the Tug Hill region. Subdivisions will negatively impact species like bobolink, which relies on hay meadows and grassy pastures for nesting. Protecting these features on large scales and delaying mowing activities until after the breeding season can have great benefits for these species.

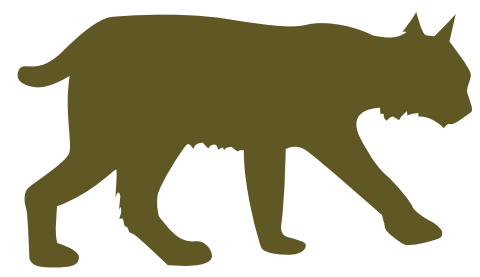

bobcat
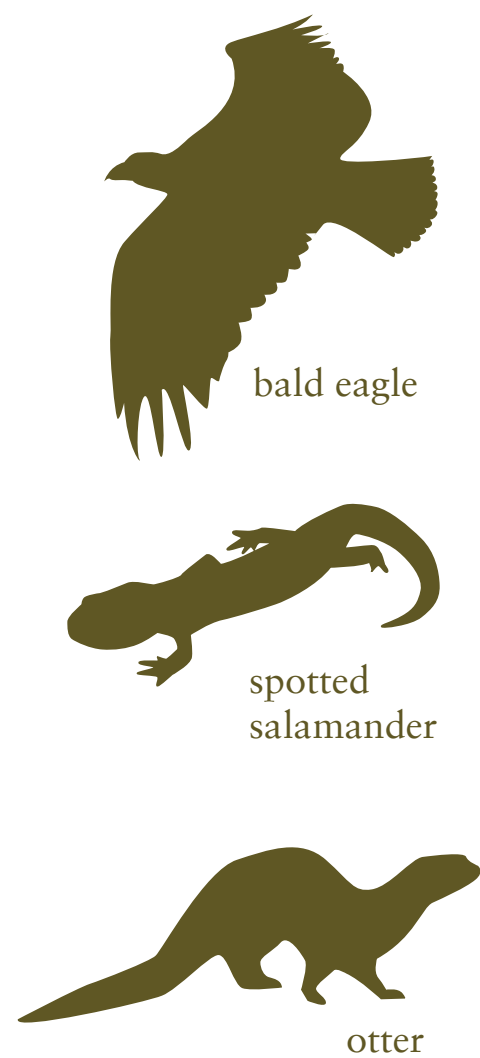

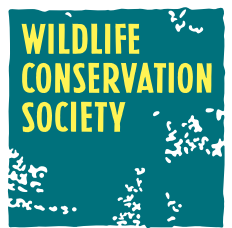

\section{ADIRONDACK PROGRAM}

7 Brandy Brook Avenue Suite 204

Saranac Lake, New York 12983

518-891-8872 www.wcs.org/adirondacks accp@wcs.org

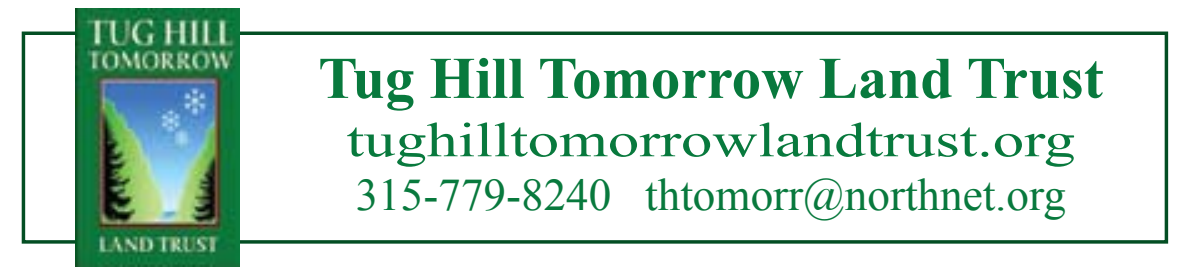

